University of Warwick institutional repository

This paper is made available online in accordance with

publisher policies. Please scroll down to view the document itself. Please refer to the repository record for this item and our policy information available from the repository home page for further information.

To see the final version of this paper please visit the publisher's website. Access to the published version may require a subscription.

Author(s: Richard James Lampard

Article Title:Party Political Homogamy in Great Britain

Year of publication: 1997

Link to published version:

http://esr.oxfordjournals.org/cgi/content/abstract/13/1/79

Publisher statement: This is a pre-copy-editing, author-produced PDF of an article accepted for publication in European Sociological Review following peer review. The definitive publisher-authenticated version Lampard, R. (1997). Party Political Homogamy in Great Britain.

European Sociological Review, 13, pp. 79-99 is available online at: http://esr.oxfordjournals.org/cgi/content/abstract/13/1/79 


\title{
PARTY POLITICAL HOMOGAMY IN GREAT BRITAIN
}

[Pre copy-editing version: August 1995]

Richard James Lampard

\author{
Department of Sociology, \\ University of Warwick, \\ UNITED KINGDOM.
}

Biographical note:

Richard Lampard is a Lecturer in Sociology at the University of Warwick. Much of his research has been in the area of marriage and divorce, but he also has research interests in social stratification and social statistics (especially the analysis of contingency tables and of event history data). He is currently working on an ESRC-funded project looking at the remarriage process.

Mailing address:

Dr. R.J. Lampard,

Department of Sociology,

University of Warwick,

Coventry CV4 7AL,

UNITED KINGDOM. 


\title{
PARTY POLITICAL HOMOGAMYIN GREAT BRITAIN
}

\begin{abstract}
This paper focuses on husbands' and wives' party political identifications in combination. There is a high level of party political homogamy in Great Britain (i.e. spouses tend to share the same party political identification). Statistical analyses show that levels of homogamy vary according to strength of party political identification, parental homogamy, age and marital status. Levels of party political similarity are also shown to differ between marriage and other social relationships, and between first marriages and remarriages. Attitudes towards homogamy are shown to vary with age. The implications of these findings for theories relating to the origins of homogamy and to the consequences of heterogamy are considered. Broadly speaking, the findings indicate that party political homogamy is a consequence of demographic constraints, utility-maximising choices, and responses to cultural norms.
\end{abstract}




\section{PARTY POLITICAL HOMOGAMYIN GREAT BRITAIN}

\section{INTRODUCTION}

Research focusing on the joint characteristics of spouses stretches back over five decades. Early studies demonstrated that there was a tendency towards homogamy (i.e. like marrying like) for a variety of characteristics. More recent research has examined trends in educational, religious, class, social status and ethnic homogamy (Penn \& Dawkins, 1983; Ultee \& Luijkx, 1990; Mare, 1991; Kalmijn, 1991a; 1991b; 1994; Lampard, 1992; Stier and Shavit, 1994).

Some pieces of recent research have focused on marital status and party politics (e.g. Kingston \& Finkel, 1987; Plutzer \& McBurnett, 1991). Other researchers have examined the effects of spouses' socio-economic characteristics on their political partisanship and voting behaviour (De Graaf and Heath, 1992; Hayes and Jones, 1992). However, while Huckfeldt and Sprague (1991) note that the analysis of political influence between spouses is worthy of extended attention, little research has been done on party political homogamy, i.e. the extent to which marriage partners have the same party political identification and/or vote the same way (though see Brickell et al., 1988). This may reflect a shortage of data corresponding to samples of couples as opposed to samples of married individuals.

In addition to its relevance to the discipline of political science, party political homogamy is also of theoretical interest in the context of theories relating to the origins and consequences of homogamy and heterogamy. Heterogamy (i.e. the marriage of dissimilar spouses) has often been viewed as a source of marital instability, despite a shortage of empirical evidence in 
support of this hypothesis (Glenn et al, 1974). The hypothesis that party political heterogamy generates marital conflict would seem as plausible as any other hypothesis focusing on a specific form of heterogamy.

Turning to the origins of homogamy, a number of different explanations have been put forward for the tendency of spouses to be similar to each other across a wide range of different characteristics. These explanations can be divided into three broad categories: cultural explanations, economic or utilitymaximisation explanations, and explanations focusing on demographic constraints. All these forms of explanation are evident, whether explicitly or implicitly, in the recent homogamy-related work of Kalmijn, whose theoretical discussions involve references to cultural matching, economic competition, preferences, opportunities and constraints (Kalmijn, 1991a; 1991b; 1994).

\section{Theoretical Explanations of Homogamy}

The first type of explanation is one which was implicitly prevalent in the first few decades of homogamy-related research. People were assumed to adhere to cultural norms which emphasised the negative and even stigmatic aspects of dissimilarity between spouses (e.g. Hollingshead, 1950; Kerckhoff, 1963).

Economic explanations of homogamy followed on from the rise to prominence of rational-choice theory. The most notable proponent of this type of explanation of homogamy is Gary Becker (Becker, 1991). Essentially this theoretical perspective focuses on the personal, primarily economic, advantages gained by marrying a partner with specific characteristics. As such the first two types of explanation are not entirely distinct from each other, since gains and losses through adherence to or rejection of cultural norms 
could be included within the framework of an economic cost-benefit analysis. In fact the overlap between the two types of explanation corresponds reasonably well to exchange theory (Blau, 1964), which is rather more sociologically-orientated than Becker's ideas.

Becker showed that assortative mating for socio-economic characteristics can be seen as a consequence of competition within the marriage market for spouses with desirable (i.e. high) levels of economic resources. The same logic cannot be used to explain party political homogamy, since it is not simply a by-product of socio-economic homogamy, and since the costs or benefits of a spouse with a particular party political identification are primarily non-economic. Party political homogamy can be expected to play a positive role in reinforcing spouses' values and beliefs, whereas party political heterogamy can be expected to generate conflict, at the very least in those cases where the disparity is an extreme one. For this reason it is probably more appropriate to think in terms of utility maximisation explanations of party political homogamy rather than in terms of economic explanations.

The final type of explanation is evident in two sets of published research. First, choice-based explanations of homogamy have been contrasted with constraint-based explanations in the debate sometimes referred to as `homogamy versus propinquity'. Various authors have attempted to ascribe at least a proportion of observed homogamy to geographical or spatial factors by asserting that residential and social segregation result in local marriage markets in which the pools of potential marriage partners are each more internally homogeneous than the pool of potential marriage partners in the 
wider population. (Kerckhoff, 1963; Catton and Smircich, 1964; Ramsoy, 1966; Peach, 1974; Morgan, 1981). Second, more overtly theoretical work by Blau has attempted to assess the impact of the distributions of people among social positions on their social relations (Blau, 1977: ix). This has led to more specific pieces of research examining the effects of the social composition of a population on intermarriage rates between the groups within it (Blau et al., 1982; Blau et al., 1984). The important aspect of Blau's work is that it emphasises the role of strictly demographic aspects of social structure in determining patterns of social association.

The dual aims of this paper are to document party political homogamy in Great Britain and to link the observed patterns to theoretical ideas relating to homogamy and heterogamy. The next section therefore uses the various theoretical explanations of the tendency towards homogamy to generate hypotheses relevant to the empirical analyses carried out in this paper.

\section{Hypotheses and Predictions relevant to the Empirical Analyses in this paper.}

This section mirrors the structure of the later section devoted to analyses and results. The starting point of that section is an examination of the extent of homogamy of party political identification and of homogamy of voting intention. This is followed by a multivariate analysis examining the effects of various relevant factors on the likelihood of homogamy.

One of these factors is strength of party political identification. While the theoretical explanations of homogamy would predict greater levels of party political homogamy than would be expected by chance, the theoretical 
explanations are a little less consistent in terms of what they would predict about the relationship between strength of party political identification and the extent of homogamy. The utility-maximisation explanation would predict a low level of homogamy among those with weak party political identifications and a high level of homogamy among those with strong party political identifications, since in terms of conflict avoidance and identity confirmation homogamy is of greater utility to the former than to the latter. The cultural explanation would predict a similar, though less marked, relationship, since people for whom politics are particularly salient may be more likely to conform to a norm of homogamy. The demographic explanation would predict a similar relationship if and only if individuals with stronger party political identifications move in significantly more homogeneous social circles than individuals with weaker party political identifications.

The multivariate analysis also examines the extent to which the children of parents who are heterogamous in terms of party political identification follow in their parents' footsteps. The utility-maximisation explanation of homogamy would seem to imply that the children of such parents should be disproportionately homogamous, since any experience of parental conflict due to heterogamy should predispose the children against heterogamy. Conversely, the cultural explanation of homogamy would suggest that these children should be disproportionately heterogamous, since their parents' marriages do not reinforce the cultural norm. The implications of the demographic explanation in this context are unclear, though arguably one might expect the children to move in similar social circles to their parents and hence have a similar tendency towards homogamy or heterogamy. 
A third factor considered in the multivariate analysis is age. A relationship between age and the extent of party political homogamy could reflect the implications of the various explanations of homogamy in a number of ways. Increasing homogamy with age could reflect a decline in the strength of the cultural norm of homogamy, or an attempt by some partners in heterogamous marriages to conform to this cultural norm by adopting the party political identification of their spouses. It could also relate to the dissolution of low utility heterogamous marriages, or to a pragmatic attempt by some partners within heterogamous couples to reduce conflict by moving in the political direction of their spouses. A demographic explanation of such a relationship would need to involve a trend in the internal party political homogeneity of the social circles into which society is divided, unless the trend related to the different levels of homogamy induced by the different demographic constraints of the marriage market and the remarriage market.

A fourth factor considered in the multivariate analysis is 'marital status' (i.e. dating; cohabiting; legally married). A relationship between marital status and the extent of homogamy could reflect the greater extent to which a cultural norm of homogamy might apply to legal marriages, or to the greater reduction in utility attached to conflict and lack of value reinforcement in a 'longer-term' relationship than in a 'shorter-term' one. It is not obvious why the tendency towards homogamy induced by demographic constraints should vary with marital status; however demographic explanations of homogamy might be pertinent to any relationship between age at marriage and homogamy, since the homogeneity of the social circles that one moves in may vary over one's life-cycle. Marriages at young ages might also be expected to 
conform less to a cultural norm of homogamy than marriages at older ages; they might also be marked by a tendency to assess the utility of relationships less accurately, which would result in a higher level of heterogamy (Becker, 1991).

A separate analysis in the empirical section of this paper considers party political homogamy in comparison with party political similarity in the context of other social relationships. If British society is to some extent stratified along party political lines, whether as a result of individual choices or simply as a result of the political homogeneity of particular social contexts, one would expect party political similarities between friends, co-workers, neighbours, etc. One would also expect some degree of party political homogeneity within families because of socialization, common economic situations, etc. The demographic explanation of party political homogamy would predict that individuals would have levels of party political similarity to their spouses comparable with their levels of similarity to other people within their social circles. The cultural and utility-maximisation explanations of homogamy would both predict that levels of similarity between spouses would be higher than levels of similarity between neighbours, friends, etc., because the cultural norm of homogamy would rule out the politically dissimilar members of the social circles that an individual moves in as potential spouses, and because the loss of utility attached to conflict with a spouse, and the gain in utility through consensus with a spouse, would be greater than the corresponding losses and gains resulting from party political dissimilarity and similarity within other forms of relationship.

The last set of empirical analyses in this paper focus on the possible 
linkage between homogamy and marital success. One issue of interest in this context is the extent to which the population perceives agreement on politics as being important for a successful marriage. The cultural explanation of homogamy would, of course, predict that a high proportion of the population would see agreement on politics as important in this context. It is less clear whether the utility-maximisation explanation would predict this, as the decision to carry on or to end a relationship which might become a marriagetype relationship may not consciously involve a recognition of the role of party politics in generating conflict or strengthening consensus. The demographic explanation would not in itself predict that agreement on politics would be perceived to be important to a successful marriage.

The final analysis in this paper focuses on differences in the extent of homogamy between first marriages and remarriages. All three explanations of homogamy are potentially relevant in this context. The cultural explanation can be argued to predict greater heterogamy in remarriages, since the divorced have failed to adhere to another marriage-related norm, i.e. life-long marriage. The utility-maximisation explanation is ambiguous in its predictions, since on one hand people marrying for a second time may be more careful in their assessment of the utility of the relationships, but on the other hand these people may be disproportionately poor at correctly assessing the utility of relationships, and hence may be inclined to enter into fragile, heterogamous marriages. The demographic explanation would predict differential levels of homogamy in relation to the relative levels of party political homogeneity of social circles within the marriage and remarriage markets; since the remarriage market is likely to be more fragmented and to involve a smaller proportion of 
the population, remarriages might be expected to be more heterogamous than first marriages.

To conclude this section, it is important to note that the degree of overlap between the predictions based on the various explanations of homogamy means that assessing their relative merits is likely to be difficult. However, by carrying out a range of empirical analyses it may be possible to generate evidence which suggests that one or more of the explanations are correct and are of particular importance.

\section{DATA SOURCES}

This paper uses data from a number of sources. The 1987 British General Election Survey (BES) surveyed a stratified multi-stage random sample of British adults aged 18 or over living in private households. Fieldwork was carried out from June to September 1987, and a 70\% response rate gave rise to an achieved sample size of 3,826 (see Heath et al., 1991: 230-234). The 1992 British General Election Survey (see Heath et al., 1993) is also used in this paper to check the validity of the data used from the 1987 survey.

The 1986 British Social Attitudes Survey (BSAS) also surveyed a stratified multi-stage random sample of British adults aged 18 or over living in private households. Fieldwork was carried out in April to May 1986, and a 70\% response rate led to an achieved sample size of 3,100 (see Jowell et al., 1987: 187-194).

The 1986 ESRC Social Change and Economic Life Initiative (SCELI) work attitudesไhistories survey surveyed random samples of adults aged between 20 and 60 in the non-institutional populations of six urban local 
labour markets in Britain (Aberdeen, Coventry, Kirkcaldy, Northampton, Rochdale and Swindon). Fieldwork was carried out in June to November 1986 and a $76 \%$ response rate led to an achieved sample size of 6,111 . The SCELI Household and Community Survey was a follow-up survey of a subset of these respondents. In this second survey, where applicable, a range of questions was asked of the respondent's partner as well as of the original respondent. Fieldwork was carried out between March and July 1987, and the response rate of this follow-up survey was $76 \%$, leading to a sample size of 1,816, of whom 1,218 were living in partnerships (see Gallie, Marsh and Vogler, 1994: 337-346).

All three of the above surveys used the electoral register as their sampling frame, and in each case the survey data have been deposited at, and are available from, the ESRC Data Archive at the University of Essex.

The BES collected data about the party political identifications both of its respondents and of some of their partners. However, there are two major limitations to these data. First, the data relating to respondents' partners were collected by a series of questions which were geared towards identifying the party political identifications of the two people with whom each respondent discussed politics most often during the 1987 General Election campaign. Consequently, if a respondent's partner was not one of these two people, no data were collected about the partner's party political identification. Second, the accuracy of the data collected depends on whether the respondent was aware of and reported correctly their partner's party political identification.

Thus analyses of the BES data need to be supported by evidence from other sources which indicate that the data are adequately representative and of 
adequate validity, e.g. data from the SCELI Household and Community Survey, which collected data on the voting intentions of a sample of respondents and their partners in separate self-completion booklets, with no collaboration being allowed between partners.

The SCELI data are themselves limited, since, while the BES was a nationally representative survey, SCELI focused on six specific study areas. However, a comparison of the data from the two sources goes some way towards establishing whether the BES data are adequately representative and of adequate validity.

Further details of the key questions from these surveys are given in footnotes to the tables. In addition to data on party political identifications and voting intentions from the BES and SCELI surveys, marriage-related attitudinal data from the 1986 BSAS are also used in this paper.

It is worth noting that the data sources used in this paper are not ideal for the examination of party political homogamy for a number of reasons. First, only limited data are available relating to respondents' partners. As a consequence it is not possible to look at the relationship between party political homogamy and various other forms of homogamy. In addition, in some of the analyses in this paper where an independent variable relates to the respondent it would be useful to have a measure of the same variable for the respondent's partner (e.g. when looking at the effect of strength of party political identification on the probability of party political homogamy). Second, the BES data do not allow one to distinguish between first marriages and remarriages. The SCELI data allow one to do this, but do not include data on the previous spouses of remarried respondents. Finally, and most 
importantly, the data sources are cross-sectional surveys which collected limited retrospective data and as such are limited in what they can show about age and cohort effects. There is no way of telling whether a couple who are currently homogamous for party political identification were homogamous in this respect at the time of their marriage. This issue will be returned to later in this paper.

\section{METHODS, ANALYSES AND RESULTS}

This section presents empirical analyses relating to party political homogamy in Great Britain. First, the extent of such homogamy is documented. A multivariate analysis looking at the effects of various pertinent factors on the likelihood of heterogamyไhomogamy is then presented. This is followed by a comparison between party political homogamy and party political similarity within other social relationships. Finally, analyses relevant to the possible relationship between party political homogamy and marital success are presented.

In addition to the use of odds ratios as measures of association, the analyses in this paper involve the use of logistic regressions and hierarchical log-linear models (Gilbert, 1993). The log-linear models were fitted using GLIM (see Francis, Green and Payne, 1993), and the logistic regressions were carried out using SPSS for Windows (Norusis, 1993).

In order to keep this paper reasonably accessible, the findings are to a large extent presented in the form of cross-tabulations and percentages rather than parameter estimates. However, since some of the factors affecting the likelihood of party political homogamy are correlated, a multivariate analysis 
(specifically in this case a logistic regression) is needed to check that each factor still has an effect when the other factors are controlled for. A multivariate analysis also allows any effects of social class and education to be identified and accounted for; note that some evidence exists that graduate couples may be unusually homogamous (Lampard, 1992).

An examination of party political homogamy might have been expected to have utilised even more elaborate multivariate analyses than those used in this paper. Recent work on assortative mating has shown how it can be useful to consider the overlap between different forms of homogamy (Kalmijn, 1991a; 1991b; 1994). However, the data sources used in this paper only allow the relationship between party political homogamy and occupational class homogamy to be examined.

More complicated multivariate models would have also been useful if the data sources available had permitted a sophisticated analysis of the effects of marriage duration, marriage cohort and period on the level of party political homogamy. However, the data sources used in this paper did not permit such an analysis. 


\section{The Extent of Party Political Homogamy}

2,606 of the BES respondents were married or living as married. Of these, 1,677 (64\%) reported that their partner was one of the two people with whom they discussed politics the most during the 1987 general election campaign. Of the other 929 respondents, 461 (18\% of the total sample) reported not having discussed politics with anybody during the election campaign and the remaining 468 (18\% of the total sample) reported having discussed politics with somebody during the election campaign, but reported that their partner was not one of the two people with whom they discussed politics the most.

Overall, of the 2,145 respondents who reported discussing politics with someone during the election campaign, 1,677 (78\%) reported that their partner was one of the two people with whom they discussed politics the most.

In addition to the married or cohabiting respondents, 109 other respondents reported that their partner was one of the two people with whom they discussed politics the most during the election campaign. This included a small number of people whose marriages had since ended, but mainly consisted of respondents who were part of couple relationships but were not married to or living with their partners. Overall, data were collected by the BES on the party political identifications of 1,786 couples.

As will be shown later in this paper, the marital status of couples is related to the level of homogamy observed. However, restricting attention to legally married couples, or to couples who were living together, has a minimal effect on the results of the other analyses in this paper, and the analyses involving the BES data are therefore based on all the available couples.

Contemporary party politics in Britain has been dominated by the (right- 
wing) Conservative party and the (left-wing) Labour party, with a third party, or alliance of parties, occupying the political middle ground. In this paper the 'Alliance' between the Liberal and Social Democratic parties is treated as a single party.

In 1,591 (89\%) of the BES couples both partners identified with one of the three `main' British political parties, though not necessarily the same party. In 47 (3\%) of the couples one partner identified with one of the three 'main' parties and the other identified with another party. In $11(1 \%)$ of the couples both partners identified with the same, 'minor' party. In the remaining 137 (8\%) of the couples, one or both partners did not identify with any party, or refused to answer the relevant question.

\section{TABLE 1 ABOUT HERE}

Table 1 shows partners' party political identifications in combination for the 1,591 couples where both partners identified with one of the three 'main' parties. In over three-quarters of the couples the partners both identified with the same party, and in only one in fourteen couples is there a Labour/Conservative disparity. (If there had been no relationship between partners' party political identifications these figures would have been just over a third and one in five respectively).

Odds ratios can be used to summarise the strength of the relationship between partners' party political identifications. Restricting attention to couples involving Conservative identifiers and Alliance identifiers, the odds

ratio is $(641 \times 203) /(86 \times 77)=19.7$. Restricting attention to couples involving Labour identifiers and Alliance identifiers, the odds ratio is (370x203)/(62x36) $=$ 33.7. Finally, restricting attention to couples involving Conservative 
identifiers and Labour identifiers, the odds ratio is $(641 \times 370) /(48 \times 68)=72.7$. Thus the implicit 'distance' between the Labour Party and the Conservative Party is greater than the distances between either of these two parties and the Alliance, with the distance between the Conservative party and the Alliance being somewhat smaller than the distance between the Labour Party and the Alliance.

\section{TABLE 2 ABOUT HERE}

An examination of data from SCELI can be used as a partial check of the validity and representativeness of the BES data on party political homogamy. Table 2 shows partners' voting intentions in combination for a sample of 738 SCELI respondents and their partners. (Attention is restricted to couples where both partners intended voting for one of the three `main' parties). As in Table 1 , in about three-quarters of the couples both partners 'supported' the same party. Rather more couples than in Table 1 were Labour/Alliance or Conservative/Alliance, but this is primarily a consequence of the greater level of support for the Alliance (i.e. about 10\% higher) in the SCELI sample than in the BES sample.

This difference in the level of Alliance support could be a consequence of the timing of the two surveys, or of the different target populations, or of the difference between identifying with a party and intending to vote for it! A more important issue is whether the patterns of association in Tables 1 and 2 differ, once the spread of support across the parties has been taken into account. This can be checked by the calculation of the three odds ratios for Table 2 that were previously calculated for Table 1 . The Conservative/Alliance odds ratio is $(201 \times 158) /(41 \times 49)=15.8$; the 
Labour/Alliance odds ratio is $(193 \times 158) /(35 \times 30)=29.0$; and the Labour/Conservative odds ratio is $(201 \times 193) /(18 \times 13)=165.8$. Hence the first two SCELI odds ratios are very similar to those from the BES sample, whereas the third SCELI odds ratio is considerably larger than that from the BES sample. This reflects the small number of Labour/Conservative couples in the SCELI sample (4\% of all couples, as opposed to $7 \%$ of all couples in the BES sample).

Tables 1 and 2 were combined to give a three-way table of husband's party by wife's party by survey. Log-linear models fitted to this table showed that both the distribution of support across the three parties and the frequency of Labour/Conservative and Conservative/Labour couples (given the distribution of support across the parties) varied significantly between the BES and SCELI samples $(\mathrm{p}<.001$ and $\mathrm{p}<.05$ respectively).

Why should there have been significantly fewer Labour/Conservative disparities in the SCELI sample? One possibility is that partners' voting intentions are more similar than their party political identifications as a consequence of tactical voting. Another is that it is a reflection of peculiarities of the SCELI study areas, though an examination of the part of the BES sample corresponding geographically to the SCELI study areas indicated that if anything the level of heterogamy should have been higher in the SCELI sample than in the BES sample. Finally, the greater level of support for the Alliance in the SCELI sample may indicate that some couples who would have appeared as Labour/Conservative or Conservative/Labour in the BES sample appeared in the SCELI sample as Labour/Alliance or Alliance/Conservative. (This is consistent with the slightly lower odds ratios 
for these two disparities in the SCELI sample as compared to the BES sample).

While some BES respondents belonging to heterogamous couples may have erroneously reported their spouses as having the same party political identifications as themselves, the fact that the frequency of Labour/Conservative disparities in the SCELI sample was significantly lower than in the BES sample suggests that the BES sample probably does not suffer much from this form of bias. Similarly, the lower frequency of disparities in the SCELI sample suggests that the BES sample is not seriously biased by a tendency for heterogamous couples to avoid discussing party politics.

In fact, more direct evidence is available in relation to this last point. Rather than asking about the two people that each respondent discussed politics with most often, the 1992 British General Election Survey asked which two people each respondent discussed important matters with the most, and later asked how often the respondent talked about politics with each of these two people. By focusing on those respondents for whom one of the two people was their spouselpartner it is possible to look at the relationship between party political homogamylheterogamy and frequency of discussing politics.

In fact, $22 \%$ of homogamous respondents reported seldom or never talking about politics with their partners, as opposed to $20 \%$ of heterogamous respondents, which suggests that the 1987 BES sample is not biased by a disproportionate exclusion of heterogamous couples as a consequence of its restriction to couples who discussed politics during the Election campaign.

Analyses of the 929 married/cohabiting BES respondents for whom data 
on spouse's party political identification were not collected showed that the sample of 1,677 BES respondents for whom these data were collected underrepresented Labour identifiers, those who did not identify with a party, and those whose party political identifications were not very strong. The next section shows that respondents in the last category are disproportionately likely to be heterogamous, hence the sample of 1,677 couples probably slightly under-represents heterogamous couples. However, an examination of the magnitude of the relationship between strength of party political identification and party political homogamy, and of the level of underrepresentation of respondents whose party political identifications were not very strong, indicates that the likely shortfall only constitutes $1 \%$ to $2 \%$ of heterogamous couples, i.e. about half-a-dozen cases.

\section{A Multivariate Analysis of Party Political Homogamy}

The next few sections discuss the results of logistic regressions with party political homogamylheterogamy as the binary dependent variable (heterogamy $=1$; homogamy $=0$ ) and various relevant factors as independent variables. Table 3 shows the results for all 1,591 respondents in Table 1; Table 4 shows the results when attention was restricted to respondents who were Labour or Conservative identifiers and who had Labour or Conservative partners. Data for quite large numbers of respondents were missing for one or more of the independent variables, thus in order to avoid a markedly reduced sample size categories such as 'not given' or 'unknown' were used for some of the independent variables.

It can be seen from Tables 3 and 4 that the effects of the social class and 
education variables are not statistically significant. Social class was based on respondent's own occupation and was operationalized using a collapsed version of the Goldthorpe class schema (Heath et al., 1991: 66), the classes used being a 'salariat', routine non-manual workers, the 'petty bourgeoisie', foremen and technicians, and a 'working class'. Class heterogamy (operationalized as one partner in the salariat and one in the working class) can be seen from Tables 3 and 4 to have a statistically insignificant effect. The education variable was based on highest qualification.

TABLES 3 AND 4 ABOUT HERE

\section{Homogamy and Strength of Party Political Identification}

It can be seen from Table 3 that the strength of a respondent's party political identification has a statistically significant effect on the likelihood of homogamy. The tendency towards heterogamy increases markedly as the strength of the respondent's party political identification decreases.

The relevant parameter estimates in Table 3 are very similar to those obtained in a bivariate analysis of the relationship between party political homogamy and strength of respondent's party political identification. A more detailed discussion of this relationship therefore follows.

Table 5 shows the relationship between strength of respondent's party political identification and partners' party political identifications in combination

\section{TABLE 5 ABOUT HERE}

The proportion of couples who are heterogamous is over three times as 
large for respondents whose party political identification was not very strong as for respondents whose party political identification was very strong. The trend is similar for all three types of heterogamous couple. The Labour/Conservative odds ratios for respondents with party political identifications which are not very strong, fairly strong, and very strong are $(124 \times 70) /(16 \times 35)=15.5,(315 \times 180) /(24 \times 25)=94.5$, and $(165 \times 96) /(7 \times 4)=$ 565.7 respectively.

In nearly half of the heterogamous couples in Table 5 the respondent's party political identification is not very strong, whereas the respondent's party political identification is very strong in less than a tenth of the heterogamous couples. (Among homogamous couples about a quarter of the respondents had very strong party political identifications and about a quarter had party political identifications that were not very strong).

Even where the respondent's party political identification is not very strong there is still nearly twice as high a proportion of homogamous couples as there would be if there were no relationship between partners' party political identifications. To some extent this may reflect the strengths of the respondents' spouses' party political identifications. However, taking the proportion at face value, it suggests that there is a tendency towards homogamy which is not a result of individuals consciously 'choosing' a politically similar partner. Conversely, the variation in heterogamy according to the strength of the respondent's party political identification visible in Table 5 suggests that much of the tendency towards homogamy is a result of conscious choice.

Returning to Table 3, the parameter estimates for turnout provide 
statistically significant evidence that heterogamy is disproportionately frequent among people who do not vote. (The variable relates to actual rather than stated voting behaviour; see Swaddle and Heath, 1989). In the BES sample $34 \%$ of married non-voters were heterogamous, as opposed to $23 \%$ of married voters (Lampard, 1992). Once again, this is consistent with the hypothesis that party political homogamy/heterogamy is related to the degree of salience of party politics to the respondent.

In the vast majority of heterogamous couples the respondent does not identify very strongly with a party, which suggests that the heterogamy may not be a problem for the couple. However, conflict is more likely where one partner objects to the party that the other partner identifies with, hence it is not so much the strength of the respondent's party political identification which is of relevance as their attitude towards the party their partner identifies with.

The BES collected data on whether respondents were 'against' specific parties. In heterogamous marriages between Labour and Conservative identifiers, 52\% (60/116) of respondents were against their partner's party. However, the percentage of respondents who were against their partner's party was much lower for heterogamous marriages involving Alliance identifiers, being 18\% (46/261). This is consistent with the hypothesis that Labour/Conservative heterogamous marriages are likely to involve the most conflict and be the most unstable. Furthermore, only 4\% (11/261) of respondents in heterogamous marriages involving an Alliance identifier were strongly against the party their partner identified with, whereas the corresponding figure for Labour/Conservative marriages was 20\% (23/116).

Since Labour\Conservative heterogamy appears to be more potentially 
problematic than other forms of party political heterogamy, the analyses in the rest of this paper focus where possible on Labour|Conservative heterogamy as well as considering party political heterogamy more broadly.

Overall, the respondent was against the party that their partner identified with in less than one in three of the heterogamous couples in Table 1, and was only strongly against their partner's party in about one in eleven of the heterogamous couples.

Hence, if one assumes that party political differences between spouses are only likely to be problematic in couples where one or both partners is against the other's party, party political differences are likely to cause problems in no more than about one in three heterogamous couples, though this figure is likely to be a slight underestimate, as it does not take account of couples where the respondent is not against their partner's party, but where the respondent's partner is against the respondent's party).

\section{The Intergenerational Transmission of Heter ogamy}

The BES collected data from its respondents on the voting behaviour of their parents when the respondents were growing up. This allows one to test the hypothesis that the children of heterogamous parents are more heterogamous than the children of homogamous parents.

Of the 1,591 respondents in the sub-sample of the BES on which Table 1 was based, 1,217 reported both their parents as having usually voted for one of the three main parties. The overall percentage of homogamous sets of parents is $88.3 \%(1,075 / 1,217)$, as compared to $76.3 \%$ of the couples in Table 1. This may indicate that some respondents were misrepresenting the voting 
behaviour of their parents. However, the odds ratio corresponding to Labour/Conservative homogamy/heterogamy among the parents is $(393 \times 610) /(31 \times 58)=133.3$, which is similar to the corresponding odds ratios in Tables 1 and 2. The difference between the parents and the couples in Tables 1 and 2 probably reflects the fact that the Alliance in 1987 was a much more heterogeneous entity than its predecessor the Liberal party had been in preceding decades.

$32 \%(46 / 142)$ of those BES respondents who reported their parents as having been heterogamous were heterogamous, compared with $23 \%$ $(246 / 1,075)$ of respondents with homogamous parents. However, the relevant parameter estimate in Table 3 is consistent with a percentage difference of this magnitude and demonstrates that parental heterogamy still significantly increases the likelihood of heterogamy net of the other independent variables in the logistic regression. (Note that the corresponding parameter estimate in Table 4, though not quite statistically significant, is marginally greater in magnitude). The inclusion of these other variables in the multivariate analysis rules out some of the most obvious explanations of the intergenerational transmission of party political homogamy.

Heterogamous parents might be expected to be less strong than average in their political identifications, and to have an 'aggregate' political identification which is towards the centre of a 'Left'/'Right' political dimension. Two reasonable assumptions about the children of heterogamous parents follow on from this. First, it seems reasonable to assume that a child of a heterogamous couple is likely to be a less strong supporter of the party they identify with than a child of a homogamous couple. The results from the 
earlier section on homogamy/heterogamy and strength of party political identification would then suggest that the first child was more likely to be in a heterogamous marriage. The second reasonable assumption is that a child of a heterogamous couple is more likely to be an Alliance identifier than a child of a homogamous couple, and Alliance identifiers are more likely to be in heterogamous marriages, hence the first child is more likely to be in a heterogamous marriage. Thus there are two fairly straightforward but rather uninteresting ways of explaining the intergenerational transmission of heterogamy.

However, the inclusion of party political identification and strength of party political identification in the logistic regression demonstrates that the intergenerational transmission of heterogamy cannot be explained in these ways.

The statistically significant parameter estimate from the logistic regression is consistent, however, with the hypothesis is that the children of party politically heterogamous parents are simply more likely to see party political heterogamy as acceptable, possibly because they do not see party politics as of salience in the marital context even if they see it as salient in other contexts.

The above findings are relevant to more general considerations of the intergenerational transmission of political attitudes, as they provide some support for the idea that such attitudes are in part culturally determined rather than simply reflecting rational economic choices (Butler and Stokes, 1974; Himmelweit et al., 1981). 


\section{Homogamy, Age and Marital Status}

It was noted in the last section that it is possible that respondents' parents were more homogamous than the respondents were. If a trend towards less homogamy exists, then one would expect there to be a relationship between party political homogamy and respondent's age. There is the standard problem of distinguishing between age and cohort effects, which will be discussed in more detail a little later. Note that respondent's age is wife's age in some cases and husband's age in others; though this is not ideal the similarity of spouses' ages on average means that it is not a serious problem.

The parameter estimate corresponding to respondent's age in Table 3 shows that respondent's age does not have a statistically significant effect on the overall likelihood of heterogamy, but the corresponding parameter estimate in Table 4 shows that respondent's age just has a significant effect on the likelihood of Labour|Conservative heterogamy. This sole age-related effect corresponds to a dichotomy contrasting respondents aged under 35 years with those aged 35 or more years.

52 out of $442(12 \%)$ of the respondents aged under 35 in Table 4 are Labour/Conservative heterogamous, as compared to 64 out of 1,149 (6\%) of the respondents aged 35 or over. Note that some of this percentage difference is spurious since it is induced by correlations between respondent's age and respondent's strength of party political identification and between respondent's age and respondent's marital status. The corresponding figures for other forms of heterogamy are 78 out of 442 (18\%) and 183 out of 1,149 (16\%).

The statistically significant relationship between respondent's age and Labour|Conservative heterogamy evident from the parameter estimate in 
Table 4 could be a reflection of three distinct time-related processes, which are difficult to distinguish between given the cross-sectional nature of the data. First, the relationship between age and Labour/Conservative heterogamy may reflect a trend across marriage cohorts towards greater heterogamy at the time of marriage. Second, it may reflect a tendency for couples within a marriage cohort to become less heterogamous with increasing marriage duration, i.e. as their marriages `age'. This decrease in heterogamy with increasing marriage duration has often been hypothesised to occur in the context of spouses' religions, though Kalmijn found no evidence in his research that this was the case (Kalmijn, 1991b). Finally, the excess of Labour/Conservative marriages at younger ages may be due to differential attrition within marriage cohorts, i.e. politically heterogamous marriages may be more likely to end in divorce.

Overall, the observed relationship is consistent with a relatively recent increase in LabourlConservative heterogamy at marriage, or a relatively quick convergence of the political identifications of some heterogamous couples as their marriages progress, or the relatively rapid dissolution of the marriages of some heterogamous couples (or a combination of the three possibilities). Note that the latter two possibilities both imply that Labour\Conservative marriages are 'problematic'; arguably the first possibility requires an unsatisfactorily abrupt change in marriage patterns.

One plausible hypothesis relating to the final possibility is that the excess of heterogamous marriages among respondents under 35 is due to 'hasty' marriages at an early age which will eventually end in divorce (cf Kiernan, 1986). However, if anything, marriages at an early age seem to be associated with increased homogamy, since 16\% (18/110) of the couples in the 
SCELI sample where the respondent had married as a teenager were heterogamous, as opposed to $26 \%(134 / 515)$ of the couples where the respondent had married in their twenties or later $(\mathrm{p}<.05)$.

Marriages at an early age may be unusually homogamous because the 'social circles' that people move in at a young age are more homogeneous with respect to party politics than those they encounter later in their adult lives. Mare has suggested a similar relationship in the context of educational homogamy (Mare, 1991: 16). A later section considers the relationship between homogamy and social context in more detail.

As noted earlier in this section, the crude relationship between age and homogamy/heterogamy partly reflects a relationship between marital status and homogamy/heterogamy. Of the 1,591 couples in Table 1, 59 were cohabiting and a further 69 were neither legally married nor cohabiting. (In addition to this, 18 respondents who discussed politics with their partner during the election campaign were widowed, divorced or separated at the time they were interviewed).

The relevant parameter estimates in Table 3 show that the general level of heterogamy is significantly higher among unmarried/non-cohabiting couples than among cohabiting couples and legally married couples. The parameter estimate corresponding to unmarried/non-cohabiting couples in Table 4 is not quite statistically significant but is of a similar magnitude to the corresponding, statistically significant, parameter estimate in Table 3.

The higher level of heterogamy among couples who are not legally married and who do not live together is consistent with the hypothesis that the importance of shared political views becomes greater as the level of 
commitment in a relationship increases. Thus it may be that people are more willing to 'date' people who do not share their political views than they are to marry/live with them.

\section{Homogamy and Social Context}

It is not just marriage partners who are similar in party political terms. Is the high level of party political homogamy simply a reflection of the party political homogeneity of the `social circles' in which people live? An analysis of BES data can go some way towards answering this question. The data on party political homogamy/heterogamy came from a question looking at the party political identifications of the two people with whom respondents discussed politics the most during the election campaign; this question can also provide evidence of respondents' party political similarity to members of their families, co-workers, neighbours and friends.

\section{TABLE 6 ABOUT HERE}

Table 6 shows the relationship between respondents' party political identifications and the party political identifications of individuals belonging to various categories of relatives/friends/acquaintances. (As in the previous analyses attention is restricted to cases where both individuals identified with one of the 'main' three parties). Each of the sub-tables only corresponds to a sub-sample of the overall BES sample. There is no guarantee that the relevant sub-sample is at all representative of the broader sample, or that the sub-tables are at all representative of the respondents' relatives/friends/acquaintances in general. Respondents may have been disproportionately likely (or disproportionately unlikely) to have discussed politics the most during the 
Election Campaign with people who shared their party political views. Thus the findings that follow are based on the assumption that the data in Table 6 are not fatally biased.

The level of party political homogamy in Table 1 (76\%) is much the same as the level of party political similarity visible in Table 6 between respondents and other members of their families living in the same household (73\%), though the percentage of Labour/Conservative disparities is rather higher in the first sub-table of Table 6 than it was in Table $1(11 \%$ as compared with 7\%). However, fewer respondents (63\%) were similar to members of their families who were not living in their households.

The level of similarity of respondents to their neighbours (65\%) was much the same as the level of similarity of respondents to members of their families who were not living in their households. However, the corresponding figure for co-workers was much lower than this (49\%). The level of similarity of respondents to friends who were not relatives or neighbours or co-workers (57\%) was also quite low relative to the level of party political homogamy in Table 1.

The high level of similarity of respondents to other family members living in the same household probably reflects the 'closeness' of the relationships involved, e.g. parent/child, respondent/sibling. The levels of similarity in the other four sub-tables of Table 6 are probably more representative of the level of similarity of respondents to the generality of individuals in the respondents' `social circles'.

Focusing on the Labour and Conservative identifiers in each sub-table, the odds ratios corresponding to the neighbours, co-workers and other friends 
sub-tables are $(76 \times 45) /(10 \times 22)=15.5,(147 \times 124) /(77 \times 58)=4.1$, and $(166 \times 125) /(65 \times 35)=9.1$ respectively, as compared to an odds ratio of 72.7 in Table 1 . Thus some of the tendency towards party political homogamy is not explained by the general level of party political similarity of respondents to the people in the 'social circles' that they move in. An important part of the tendency to party political homogamy appears to be a tendency for individuals to choose a partner whose party political views match their own. The data in Table 6 suggest that it is implausible that the observed level of party political homogamy is entirely a consequence of structural constraints.

Conversely, the levels of similarity obtained from the sub-tables of Table 6 suggest that there are structural effects which to an extent lead to party political homogamy. Of course, individuals exercise a certain amount of control over who their neighbours, co-workers and other friends are but decisions leading to individuals moving in particular 'social circles' are probably largely based on factors other than the individual's perception of the party political views of the people within those social circles, and the party political homogeneity of many 'social circles' is not something over which individuals can exert much control.

Note that the above discussion hinges on the assumption that the data analysed are adequately representative of the 'social circles' within which the respondents move.

The above findings are consistent with the view of Huckfeldt and Sprague that the relationship between individual political attitudes and the prevalent political attitudes in a locality reflect both individual choices and structural constraints (Huckfeldt and Sprague, 1991; Huckfeldt, Plutzer and 
Sprague, 1993).

\section{Homogamy and Marital Success}

While heterogamy is often thought to reduce marital quality and/or increase marital instability, there is very little evidence to support this hypothesis, except in the case of age heterogamy (Lampard, 1992), and possibly educational heterogamy (Tzeng, 1992). However, BSAS data suggest that many people see homogamy as important to the success of a marriage. Respondents were provided with a list of factors which might affect the success of a marriage and were asked the question "How important is each one to a successful marriage?". Respondents could rate the factors as "Very Important", "Fairly Important", "Not Very Important" and "Not At All Important". Four of the listed factors were homogamy-related, i.e. "Tastes and interests in common", "Same social background", "Shared religious beliefs", and "Agreement on politics".

"Agreement on politics" was rated as very or fairly important by $15 \%$ $(239 / 1,552)$ of respondents. However, the corresponding figures for "Tastes and interests in common", "Same social background", and "Shared religious beliefs" were 79\%, 48\% and 37\% respectively. Thus, though party political homogamy is even more common in Britain than homogamy of social origin, it is not seen as of the same degree of importance in the context of marital success.

The above findings may reflect a public perception of politics as of little relevance to everyday life and social interactions. Thus while the party political homogamy evident in Table 1 reflects the underlying socio-political 
values and beliefs of BES respondents and their partners, BSAS respondents may not have interpreted "agreement on politics" as meaning "agreement on attitudes towards important socio-political issues". Additionally, the 'dire consequences' of religious intermarriage, marrying `cross-class', and marrying a spouse with different tastes and interests are probably more entrenched in British minds than the negative consequences of political differences between spouses are (possibly as a consequence of the infrequency of such political differences).

54\% (126/235) of BSAS respondents who saw "agreement on politics" as important saw all three other homogamy-related factors as important and hence believed similarity between spouses to be important in general. However, only 37\% (126/339) of those respondents who saw all three other factors as important saw "agreement on politics" as important. BSAS data also show that there is virtually no variation in the percentage of respondents who see "agreement on politics" as important according to party political identification (with the figure falling into the range 14\% to $17 \%$ for all three main parties).

\section{TABLE 7 ABOUT HERE}

More interesting, given this paper's earlier findings on trends in party political homogamy, is the relationship between age and attitude towards the importance of "agreement on politics". Table 7 shows that as age decreases so the perceived importance of "agreement on politics" decreases. A log-linear model fitted to Table 7 showed the relationship between age and this attitude to be statistically significant $(\mathrm{p}<.001)$.

This finding probably does not explain the greater level of party 
political heterogamy among the under 35's which was noted earlier in the paper, since the trend visible in Table 7 is spread across all four age categories.

One hypothesis is that Table 7 provides evidence of a general decline in the perceived salience of a variety of factors which have historically structured social interactions such as marriage. There is only evidence that actual salience has declined during the latter part of the 20th Century for a few of the various factors for which there is a tendency towards homogamy e.g. social origin, Christian denomination (Lampard, 1992). However, there is no reason why people should not be increasingly perceiving a factor as being of decreasing relevance, though its actual salience is static.

Similar relationships exist in the BSAS data between age and the perceived importance of the other three marriage-related factors. The decline in importance is least evident for "Tastes and interests in common".

\section{TABLE 8 ABOUT HERE}

SCELI collected rather more 'concrete' data on the relationship between marital stability and party political homogamy/heterogamy. Table 8 compares homogamy/heterogamy of voting intention between respondents in their first marriages and respondents in their second (or later) marriages (following at least one divorce). $24 \%$ of the first marriages were heterogamous as compared with $31 \%$ of the remarriages. Log-linear models showed that this statistically significant difference $(\mathrm{p}<.001)$ is due to a disproportionate number of remarriages involving Labour/Conservative disparities. (13\% of the remarriages involved Labour/Conservative disparities as opposed to 3\% of the first marriages). 
The above relationship may occur as a consequence of people who tend towards party political heterogamy having an unusually high risk of marital dissolution and hence being disproportionately represented among remarriages. Alternatively, remarriages may be more heterogamous as a consequence of a marriage market which makes homogamous marriages difficult to come by for the previously married (c.f. Dean \& Gurak, 1978).

Ideally, one would have access to data relating to homogamylheterogamy in the first marriages of remarried people. This would allow one to distinguish between the two explanations offered above. However, it is very rare for surveys to collect retrospective data about respondents' ex-spouses. Note also that remarriages involve only a subset of those whose first marriages have ended. 


\section{SUMMARY AND DISCUSSION}

\section{Summary of findings}

This paper contains a number of interesting empirical findings relating to husbands' and wives' party political identifications in combination in Great Britain. The vast majority of British couples were found to be homogamous for party political identification. People whose support for the party that they identified with was not very strong were found to be disproportionately likely to have been part of a heterogamous couple, and members of heterogamous couples were found to have been `against' the party that their partner identified with in only a minority of cases.

The relationship between strength of party political identification and party political homogamy remained strong in the context of a multivariate analysis of party political heterogamy which included a number of other relevant factors. In this multivariate analysis heterogamy was found to be disproportionately frequent among people with heterogamous parents, people aged less than 35, and people who were neither legally married to nor cohabiting with their partners.

The level of similarity of party political identification between marriage partners was found to be similar to the level of similarity between relatives living in the same household, but greater than the level of similarity in other relationships

'Agreement on politics' was only thought to be important to a successful marriage by a small minority of people, and was thought less important in this context than other forms of similarity. Older people were found to be more likely than younger people to see agreement on politics as important. 
Finally, Labour/Conservative disparities in voting intention were found to be significantly more frequent among remarriages than among first marriages.

\section{The theor etical relevance of patterns of party political homogamy}

Party political homogamy should be of interest to political scientists, since the salience of party political identification in the context of partner selection can be viewed as part of the broader salience of party politics to an individual's life in general. The extent of party political homogamy and any trends in party political homogamy may well reflect the extent to which we demand spouses who share our views of the world, but may also reflect the extent to which we see party politics as relevant to our day-to-day lives. Additionally, if homogamy of party political identification is seen to be partly a consequence of the 'stratification' of society by political attitudes, and given that the distribution of party political support is already known to vary between different geographical areas and different occupational groups, it would be interesting to discover the extent to which 'social circles' are homogeneous with respect to party political identification. However, an examination of party political homogamy can also contribute to our understanding of the relationship between heterogamy and marital instability, and also our understanding of the origins of homogamy.

The impact of heterogamy of party political identification on marital stability is at least as worthy of study as the impact of various other forms of heterogamy, especially since differences in political viewpoint are perhaps a more obvious source of conflict than differences in family or educational 
background.

A number of the empirical results in this paper shed some light on the relationship between party political homogamy and marital instability. First of all, most couples who are heterogamous in this respect do not have very strong party political identifications, and are not against their partners' parties. Agreement on politics was also shown to be viewed as less important to a successful marriage than other forms of homogamy. Thus party political homogamy is not explicitly a universal cultural norm, and party political heterogamy in itself should not be automatically assumed to reduce the utility of marriages by generating conflict. Conversely, agreement on politics was shown to be important to some people, and in half of the LabourlConservative couples the respondent was against their partner's party, suggesting that there may be potential for utility-reducing conflict within these couples. The analysis of party political homogamy in relation to age provides some evidence in support of this last possibility since it indicated that Labour\Conservative heterogamous couples may be disproportionately prone to marital dissolution, or may tend to deal with the problematic disparity by becoming homogamous. (This assumes that there has been no abrupt trend towards LabourlConservative heterogamy). Additionally, the greater level of party political heterogamy among remarriages may reflect a relationship between party political heterogamy and marital instability in first marriages (i.e. individuals who tend to be heterogamous may also tend to have unstable marriages because they reject all marriage-related cultural norms, or because they are bad at assessing the utility of relationships). Note, however, that the pattern could also reflect a greater level of contact between politically 
dissimilar people within the remarriage market. Overall, the evidence appears consistent with the idea that some extremely heterogamous couples may be at an increased risk of marital dissolution if they remain heterogamous.

The results also shed some light on the relative merits of the various theoretical explanations of the origins of party political homogamy. Demographic constraints appear to be important. There is a significant level of homogamy among people whose party political identifications are not very strong, which possibly reflects the party political homogeneity of the social circles that those people move in more than it reflects individual choice. Evidence for this party political homogeneity comes from the finding that many forms of social relationships are marked by party political similarity. As noted above, agreement on politics is not perceived as particularly important to a successful marriage, despite the high levels of observed party political homogamy. This apparent rejection of the cultural importance of party political homogamy strengthens the argument that it originates from demographic constraints. It is also difficult to see what utility is gained from party political homogamy among relatively apolitical people in the absence of a strong cultural norm of party political homogamy. Furthermore, the observed relationship between age and the perceived importance of agreement on politics suggests that the cultural importance of party political homogamy may be declining, while observed levels of party political homogamy remain more or less constant. Once again, this downplays the importance of cultural explanations of homogamy relative to explanations relating to demographic constraints. Finally, both the high level of party political homogamy for young ages at marriage and the high level of party political heterogamy for 
remarriages can be explained in terms of the homogeneitylheterogeneity of social circles $\backslash$ marriage markets, with the former being difficult to explain by reference to the cultural or utility-maximisation explanations of homogamy.

The empirical findings in this paper also provide some support for the cultural and utility-maximisation explanations of party political homogamy. Some findings, for example the high level of heterogamy among noncohabiting couples, and the greater level of similarity between marriage partners than is evident in other forms of social relationship, are equally consistent with cultural and utility-maximising explanations. (In both these examples similarity is greater in the more 'involved' form of relationship, which either reflects a greater pressure to adhere to cultural norms, or a greater need to avoid the loss in utility resulting from dissimilarity).

However, some of the other findings seem to sit more comfortably alongside one of these two explanations than the other. The high level of party political homogamy among those with very strong party political identifications is probably an example of a strong tendency towards homogamy among a group for whom heterogamy would involve a great reduction in utility. Conversely, the intergenerational transmission of party political homogamylheterogamy (presumably via socialization) is most easily explained in cultural terms. Additionally, the fact that some people see agreement on politics as important to a successful marriage provides support for the idea of a cultural norm of homogamy, albeit a weak one, whereas the probable vulnerability of some heterogamous couples, i.e. Labour|Conservative couples, gives credence to the utility-maximisation explanation. Note, as mentioned earlier in this paper, that these two forms of 
explanation are not mutually exclusive; the utility-maximisation explanation of party political homogamy would benefit from an assessment of the costs and benefits of adhering to cultural norms.

In conclusion, the findings in this paper are consistent with a theory of the origins of party political homogamy which incorporates demographic constraints, individual choices geared towards maximising the utility of marriage, and responses to cultural pressures. The difficulty inherent in trying to identify whether party political homogamy reflects a cultural norm of homogamy or the aggregated choices of rational social actors relates to the familiar issue of the relative roles played by structure and agency in determining social behaviour. However, this paper has indicated that a third possibility needs to be considered, i.e. that homogamy at least partially reflects the fact that society is an aggregation of a myriad of internally homogeneous 'social circles'. This is not a novel observation (see Henry, 1972), but it is an important one, especially given that it is quite possible that the origins and consequences of other forms of social homogamy are similar to the origins and consequences of party political homogamy.

\section{ACKNOWLEDGEMENTS:}

I am grateful to Cherrill Hicks, Jim Beckford and Anthony Heath for inspiring me to write this paper and to Tony Elger and various referees for their helpful comments and suggestions. I am also grateful to Duncan Gallie and Anthony Heath for giving me access to some of the data sources used. 
TABLE 1 Husband's party political identification (PPI) and wife's party political identification in combination

\section{Wife's PPI}

Husband's PPI Cons've Labour All'nce

Conservative $\quad 641(40.3 \%) 48(3.0 \%) \quad 86(5.4 \%)$

Labour $\quad 68(4.3 \%) \quad 370(23.3 \%) 62(3.9 \%)$

Alliance $\quad 77(4.8 \%) \quad 36(2.3 \%) \quad 203(12.8 \%)$

Notes:

$n=1,591$. Data from BES (see text). Percentages relate to the total number of cases in the table.

Respondent's party political identification was obtained from Question 12 on the interview questionnaire: "Generally thinking, do you think of yourself as Conservative, Labour, Liberal, Social Democrat... or what?" and (if the respondent answered "No" or "Don't know") "Do you generally think of yourself as a little closer to one of the Parties than the other?".

Respondent's partner's party political identification was obtained from Question 22 on the self-completion questionnaire: "Please think of the two people you discussed politics with most often, during the election campaign", "What relationship is this person to you" [one category was husband/wife/partner], and "As far as you know, does this person think of himself or herself as Conservative, Labour, SDP or Liberal or Alliance... or something else?". 
TABLE 2 Husband's voting intention (VI) and wife's voting intention in combination

\begin{tabular}{llll}
\hline \hline & \multicolumn{2}{c}{ Wife's VI } & \\
Husband's VI & Cons've & Labour & All'nce \\
Conservative & $201(27.2 \%)$ & $18(2.4 \%)$ & $49(6.6 \%)$ \\
Labour & $13(1.8 \%)$ & $193(26.2 \%)$ & $35(4.7 \%)$ \\
Alliance & $41(4.8 \%)$ & $30(4.1 \%)$ & $158(21.4 \%)$ \\
\hline \hline
\end{tabular}

Notes:

$\mathrm{n}=738$. Data from SCELI (see text). Percentages relate to the total number of cases in the table.

Respondents' and respondents' partners voting intentions were obtained from Questions 122 and 123 on their respective selfcompletion questionnaires: "If there was a general election tomorrow would you vote?" and "Which political party would you vote for?". 
TABLE 3 Logistic regression analysis of party political heterogamy

\begin{tabular}{|c|c|c|c|c|}
\hline $\begin{array}{l}\text { Independent } \\
\text { variable }\end{array}$ & $\begin{array}{l}\text { Parameter } \\
\text { stimate (B) }\end{array}$ & $\begin{array}{l}\text { Standard } \\
\text { Error }\end{array}$ & $\begin{array}{c}\mathrm{P} \\
\text { Value }\end{array}$ & $\operatorname{Exp}(B)$ \\
\hline \multicolumn{3}{|l|}{ Party Political ID } & $\odot .000$ & \\
\hline Conservative & 0.000 & & & \\
\hline Labour & 0.396 & 0.157 & 0.012 & 1.486 \\
\hline Alliance & 1.019 & 0.155 & $\odot .0 \odot \odot$ & 2.770 \\
\hline \multicolumn{3}{|l|}{ Strength of party ID } & 0.000 & \\
\hline Very strong & $\odot .000$ & & & \\
\hline Fairly strong & $\odot .800$ & 0.208 & $\odot .000$ & 2.226 \\
\hline Not very strong & 1.503 & 0.216 & 0.000 & 4.494 \\
\hline Not states & 0.497 & 0.362 & 0.169 & 1.644 \\
\hline \multicolumn{3}{|c|}{ Voted in 1987 (turnout) } & $\odot .019$ & \\
\hline Yes & 0.000 & & & \\
\hline No & 0.505 & 0.186 & 0.007 & 1.658 \\
\hline Unknown & -0.183 & 0.336 & 0.587 & 0.833 \\
\hline \multicolumn{2}{|l|}{ Parental marriage } & & 0.054 & \\
\hline Homogamous & 0.000 & & & \\
\hline Heterogamous & 0.469 & 0.206 & 0.023 & 1.598 \\
\hline Unknown & -0.055 & 0.153 & 0.720 & 0.947 \\
\hline \multicolumn{2}{|l|}{ Respondent's age } & & 0.510 & \\
\hline Under 35 years & 0.000 & & & \\
\hline 35 or more years & -0.122 & 0.152 & 0.423 & 0.885 \\
\hline Unknown & 0.494 & 0.709 & 0.486 & 1.639 \\
\hline \multicolumn{2}{|l|}{ Marital status } & & $\odot .014$ & \\
\hline Legally married & 0.000 & & & \\
\hline Cohabiting & 0.034 & 0.331 & $\odot .918$ & 1.035 \\
\hline Neither & 0.760 & 0.262 & $\odot .0 \odot 4$ & 2.137 \\
\hline \multicolumn{2}{|l|}{ Social class } & & 0.336 & \\
\hline Salariat & $\odot .0 \odot \odot$ & & & \\
\hline Routine non-manual & -0.286 & 0.181 & 0.115 & 0.751 \\
\hline Petty bourgeoisie & -0.521 & $\odot .296$ & 0.079 & 0.594 \\
\hline Foreman\technician & -0.297 & 0.333 & 0.372 & 0.743 \\
\hline Working class & -0.024 & 0.187 & 0.900 & 0.977 \\
\hline Unclassifiable & -0.258 & 0.496 & 0.603 & 0.773 \\
\hline \multicolumn{2}{|c|}{ Highest qualification } & & 0.322 & \\
\hline None of below & 0.000 & & & \\
\hline 'o' level & $\odot .088$ & 0.162 & 0.589 & 1.092 \\
\hline 'A' level \Degree & $\odot .289$ & 0.193 & 0.134 & 1.335 \\
\hline \multicolumn{2}{|l|}{ Occupational homogamy } & & 0.920 & \\
\hline Heterogamy & 0.000 & & & \\
\hline Homogamy & $-\odot .099$ & 0.245 & 0.685 & 0.906 \\
\hline Unknown & -0.027 & 0.396 & 0.947 & $\odot .974$ \\
\hline Constant & -0.781 & 0.311 & 0.012 & \\
\hline
\end{tabular}

Notes: $n=1,591$. Data from BES ( see text).

Scaled deviance $=1569.2$

Change in deviance from null model $=173.1$ on 22 degrees of freedom $(p=0.000)$ 
TABLE 4 Logistic regression analysis of party political heterogamy: Labour and Conservative respondents and partners only

\begin{tabular}{|c|c|c|c|c|}
\hline $\begin{array}{l}\text { Independent } \\
\text { variable }\end{array}$ & $\begin{array}{l}\text { Parameter } \\
\text { Estimate (B) }\end{array}$ & $\begin{array}{l}\text { Standard } \\
\text { Error }\end{array}$ & $\begin{array}{c}\mathrm{P} \\
\text { Value }\end{array}$ & $\operatorname{Exp}(B)$ \\
\hline \multicolumn{3}{|l|}{ Party Political ID } & 0.006 & \\
\hline Conservative & 0.000 & & & \\
\hline Labour & 0.601 & 0.221 & 0.006 & 1.823 \\
\hline \multicolumn{3}{|l|}{ Strength of party ID } & $\odot . \odot \odot \odot$ & \\
\hline Very strong & 0.000 & & & \\
\hline Fairly strong & 0.766 & 0.351 & 0.029 & 2.152 \\
\hline Not very strong & 1.759 & $\odot .359$ & 0.000 & 5.808 \\
\hline Not states & 0.576 & $\odot .569$ & 0.311 & 1.779 \\
\hline \multicolumn{3}{|c|}{ Voted in 1987 (turnout) } & 0.005 & \\
\hline Yes & 0.000 & & & \\
\hline No & 0.826 & 0.278 & 0.003 & 2.283 \\
\hline Unknown & 0.679 & 0.422 & 0.107 & 1.973 \\
\hline \multicolumn{2}{|l|}{ Parental marriage } & & 0.164 & \\
\hline Homogamous & 0.000 & & & \\
\hline Heterogamous & 0.597 & 0.336 & 0.076 & 1.816 \\
\hline Unknown & $-\odot .080$ & 0.256 & 0.755 & 0.923 \\
\hline \multicolumn{2}{|l|}{ Respondent's age } & & 0.119 & \\
\hline Under 35 years & 0.000 & & & \\
\hline 35 or more years & -0.491 & 0.245 & 0.045 & 0.612 \\
\hline Unknown & 0.255 & 1.236 & 0.837 & 1.290 \\
\hline \multicolumn{2}{|l|}{ Marital status } & & 0.162 & \\
\hline Legally married & $\odot .00 \odot$ & & & \\
\hline Cohabiting & 0.184 & 0.437 & 0.673 & 1.202 \\
\hline Neither & 0.722 & 0.379 & 0.057 & 2.058 \\
\hline \multicolumn{2}{|l|}{ Social class } & & 0.335 & \\
\hline Salariat & 0.000 & & & \\
\hline Routine non-manual & -0.038 & 0.311 & 0.904 & 0.963 \\
\hline Petty bourgeoisie & -0.834 & 0.556 & 0.134 & 0.435 \\
\hline Foreman\technician & 0.163 & 0.483 & 0.735 & 1.177 \\
\hline Working class & 0.334 & 0.319 & $\odot .295$ & 1.397 \\
\hline Unclassifiable & -6.958 & 11.546 & 0.547 & 0.001 \\
\hline \multicolumn{2}{|c|}{ Highest qualification } & & 0.593 & \\
\hline None of below & 0.000 & & & \\
\hline 'o' level & 0.269 & 0.268 & 0.315 & 1.308 \\
\hline 'A' level\Degree & 0.209 & 0.344 & 0.543 & 1.233 \\
\hline \multicolumn{2}{|l|}{ Occupational homogamy } & & 0.718 & \\
\hline Heterogamy & $\odot .00 \odot$ & & & \\
\hline Homogamy & -0.041 & $\odot .397$ & 0.917 & 0.960 \\
\hline Unknown & 0.530 & 0.663 & 0.424 & 1.700 \\
\hline Constant & -2.452 & 1.984 & 0.217 & \\
\hline
\end{tabular}

Notes: $n=1,127$. Data from BES ( see text).

Scaled deviance $=656.7$

Change in deviance from null model $=90.4$ on 21 degrees of freedom $(p=0.000)$ 
TABLE 5 Husband's party political identification (PPI) and wife's party political identification in combination according to the strength of the respondent's party political identification

$\underline{\text { Respondent's PPI }=\text { Very strong }}$

Wife's PPI

Husband's PPI Cons've Labour All'nce

Conservative $165(51.1 \%) 7(2.2 \%) \quad 4$ (1.2\%)

Labour $\quad 4(1.2 \%) \quad 96(29.7 \%) \quad 4(1.2 \%)$

Alliance $\quad 12(3.7 \%) \quad 3(0.9 \%) \quad 28(8.7 \%)$

Respondent's PPI $=$ Fairly strong

Wife's PPI

Husband's PPI Cons've Labour All'nce

Conservative $315(42.1 \%) 24$ (3.2\%) 37 (4.9\%)

Labour $\quad 25$ (3.3\%) $180(24.1 \%) 23(3.1 \%)$

Alliance $\quad 35(4.7 \%) \quad 17(2.3 \%) \quad 92(12.3 \%)$

$\underline{\text { Respondent's PPI }=\text { Not very strong }}$

Wife's PPI

Husband's PPI Cons've Labour All'nce

Conservative $124(28.2 \%) 16(3.6 \%) \quad 43$ (9.8\%)

Labour $\quad 35(8.0 \%) \quad 70(15.9 \%) \quad 33(7.5 \%)$

Alliance $\quad 27(6.2 \%) \quad 15$ (3.4\%) 76 (17.3\%)

Notes:

Overall, $n=1,510$. Data from BES (see text). Percentages relate to the total number of cases in each sub-table; $n=323, n=748$ and $\mathrm{n}=439$ respectively.

Data on strength of respondent's party political identification was obtained from Question 12(c): "Would you call yourself very strong [Conservative, Labour, etc.], fairly strong or not very 
strong?". 81 cases included in Table 1 were omitted from Table 5 because they did not answer 12(c) or answered "Don't know". 
TABLE 6 Respondent's party political (PPI) identification in combination with the party political identifications of various categories of relatives, friends and acquaintances

Family members in respondent's household

(other than respondent's partner)

Family member's PPI

Respondent's PPI Cons've Labour All'nce

Conservative $193(34.6 \%) 31(5.6 \%) \quad 28$ (5.0\%)

Labour $\quad 30(5.4 \%) \quad 154(27.6 \%) 13(2.3 \%)$

Alliance $\quad 30(5.4 \%) \quad 18(3.2 \%) \quad 60(10.8 \%)$

Family members not in respondent's household

(other than respondent's partner)

Family member's PPI

Respondent's PPI Cons've Labour All'nce

Conservative $131(28.7 \%) 42$ (9.2\%) 27 (5.9\%)

Labour $\quad 28(6.1 \%) 117(25.7 \%) 16$ (3.5\%)

Alliance $\quad 31(6.8 \%) \quad 27$ (5.9\%) 37 (8.1\%)

$\underline{\text { Neighbours }}$

\section{Neighbour's PPI}

Respondent's PPI Cons've Labour All'nce

Conservative $\quad 76(35.5 \%) \quad 10(4.7 \%) \quad 13(6.1 \%)$

Labour $\quad 22(10.3 \%) \quad 45(21.0 \%) 11(5.1 \%)$

Alliance $\quad 10(4.7 \%) \quad 9(4.2 \%) \quad 18(8.4 \%)$

$\underline{\text { Co-workers }}$

\section{Co-worker's PPI}

Respondent's PPI Cons've Labour All'nce

Conservative $147(23.7 \%) 77(12.4 \%) 44(7.1 \%)$

Labour $\quad 58$ (9.3\%) $124(20.0 \%) 23(3.7 \%)$

Alliance $\quad 52(8.4 \%) \quad 63(10.1 \%) \quad 33(5.3 \%)$ 
Other friends

\section{Other friend's PPI}

Respondent's PPI Cons've Labour All'nce

Conservative $166(28.2 \%) 65(11.1 \%) \quad 36$ (6.1\%)

Labour

$35(6.0 \%) 125(21.3 \%) 25$ (4.3\%)

Alliance

$41(7.3 \%) \quad 51(8.7 \%) \quad 44(7.5 \%)$

Notes: Data from BES (see text and Table 1). Percentages relate to the total number of cases in each sub-table; $n=557, n=456, n=621$, $\mathrm{n}=214$, and $\mathrm{n}=588$ respectively. 
TABLE 7 The relationship between age and respondent's perception of the importance of "agreement on politics" to a successful marriage

\begin{tabular}{lccll}
\hline \hline Age & $\begin{array}{c}\text { Very } \\
\text { Important }\end{array}$ & $\begin{array}{l}\text { Fairly } \\
\text { Important }\end{array}$ & $\begin{array}{l}\text { Not Very } \\
\text { Important }\end{array}$ & $\begin{array}{l}\text { Not At All } \\
\text { Important }\end{array}$ \\
Under 35 & $6(1.2 \%)$ & $47(9.7 \%)$ & $262(53.9 \%)$ & $171(35.2 \%)$ \\
35 to 49 & $6(1.4 \%)$ & $49(11.3 \%)$ & $264(61.0 \%)$ & $114(26.3 \%)$ \\
50 to 64 & $15(4.2 \%)$ & $44(12.3 \%)$ & $200(55.9 \%)$ & $99(27.7 \%)$ \\
65 or over & $14(5.5 \%)$ & $58(22.8 \%)$ & $136(53.5 \%)$ & $46(18.1 \%)$ \\
\hline \hline
\end{tabular}

Notes:

Data from BSAS (see text). Percentages in each row add up to $100 \% ; n=1,531$. 
TABLE 8 Homogamy/heterogamy of voting intention compared between first marriages and remarriages

$\underline{\text { Respondents in their first marriages }}$

Wife's voting

Husband's voting intention

intention

Con Lab

All

Conservative

$171(27.2 \%) \quad 7(1.1 \%) \quad 35(5.6 \%)$

Labour

$11(1.8 \%) 165(26.3 \%) 27$ (4.3\%)

Alliance

$41(6.5 \%) \quad 32(5.1 \%) \quad 139(22.1 \%)$

$\underline{\text { Respondents in second or later marriages }}$

(following at least one divorce)

Wife's voting

Husband's voting intention

intention

Con

Lab

All

Conservative

$23(32.4 \%) \quad 4(5.6 \%) \quad 4(5.6 \%)$

Labour

$5(7.0 \%) \quad 13(18.3 \%) \quad 0(0.0 \%)$

Alliance

$7(9.9 \%)$

$2(2.8 \%)$

$13(18.3 \%)$

Notes:

Data from SCELI (see text). The Percentages in each sub-table add up to $100 \%$, and the sample sizes in the two sub-tables are $n=628$ and $\mathrm{n}=71$ respectively.

Details of log-linear models fitted to the above table:
$[\mathrm{A}]=$ Wife's voting intention
$[\mathrm{B}]=$ Husband's voting intention
$[\mathrm{C}]=$ First marriage or remarriage
[D] = Factor differentiating between couples involving a disparity between Labour and Conservative and all other couples 


\begin{tabular}{|c|c|c|}
\hline Model & Deviance & Change in deviance \\
\hline$[\mathrm{AB}][\mathrm{AC}][\mathrm{BC}]$ & 15.5 on 4 d.f. $(p<.01)$ & \\
\hline$+[\mathrm{CD}]$ & 4.3 on 3 d.f. $(p>.05)$ & 11.2 on 1 d.f. $(p<.001)$ \\
\hline
\end{tabular}




\section{REFERENCES:}

Becker G S. (1991): A Treatise on the Family (2nd edition). Cambridge: Harvard University Press.

Blau P M. (1964): Exchange and Power in Social Life. New York: Wiley.

Blau P M. (1977): Inequality and Heterogeneity. New York: Free Press.

Blau P M, Beeker C, Fitzpatrick K M. (1984): `Intersecting Social Affiliations and Intermarriage', Social Forces, 62.3: 585-606.

Blau P M, Blum T C, Schwartz J E. (1982): 'Heterogeneity and Intermarriage', American Sociological Review, 47.1: 45-61.

Brickell B, Huckfeldt R, Sprague J. (1988): Gender Effects on Political Discussion: The Political Networks of Men and Women. Paper presented at the annual meeting of the Midwest Political Science Association, Chicago.

Butler D, Stokes D. (1974): Political Change in Britain (2nd Edition). London: Macmillan.

Catton W R, Smircich R J. (1964): `A Comparison of Mathematical Models for the Effect of Residential Propinquity on Mate Selection', American Sociological Review, 29.4: 522-529.

De Graaf N D, Heath A. (1992): 'Husbands' and Wives' Voting-behaviour in Britain: Class-dependent Mutual Influence of Spouses', Acta Sociologica, 35: 311-322.

Dean G, Gurak D T. (1978): 'Marital homogamy the second time around', Journal of Marriage and the Family, 40.3: 559-570.

Francis B, Green M, Payne C. (eds) (1993): The GLIM System: Release 4 Manual. Oxford: Oxford University Press. 
Gallie D, Marsh C, Vogler C. (eds) (1994): Social Change and the Experience of Unemployment. Oxford: Oxford University Press.

Gilbert G N. (1993): Analysing Tabular Data: Loglinear and Logistic Models for Social Researchers. London: UCL Press.

Glenn N D, Hoppe S K, Weiner D. (1974): ` Social Class Heterogamy and Marital Success: A Study of the Empirical Adequacy of a Textbook Generalization', Social Problems, 21: 539-550.

Hayes B, Jones F L. (1992): `Marriage and Political Partisanship - Do Wives' Characteristics Make a Difference?', Sociology, 26: 81-101.

Heath A, Curtice J, Jowell R, Evans G, Field J, Witherspoon S. (1991): Understanding Political Change. Oxford: Pergamon Press.

Heath A, Jowell R, Curtice J. (eds) (1993): Labour's Last Chance: The 1992 Election and Beyond. Aldershot: Dartmouth.

Henry L. (1972): `Nuptiality', Theoretical Population Biology, 3: 135-152.

Himmelweit H, Humphreys P, Jaegar M, Katz M. (1981): How Voters Decide. London: Academic Press.

Hollingshead A B. (1950): 'Cultural factors in the selection of marriage mates', American Sociological Review, 15: 619-627.

Huckfeldt R, Plutzer E, Sprague J. (1993): `Alternative Contexts of Political Behaviour - Churches, Neighborhoods and Individuals', Journal of Politics, 55.2: 365-381.

Huckfeldt R, Sprague J. (1991): `Discussant Effects on Vote Choice: Intimacy, Structure and Independence', Journal of Politics, 53.1: 122-158.

Jowell R, Witherspoon S, Brook L. (eds) (1987): British Social Attitudes: the 
1987 report. Aldershot: Gower.

Kalmijn M. (1991a): 'Status homogamy in the United States', American Journal of Sociology, 97.2: 496-523.

Kalmijn M. (1991b): `Shifting boundaries: Trends in religious and educational homogamy', American Sociological Review, 56: 786-800.

Kalmijn M. (1994): `Assortative mating by cultural and economic occupational status', American Journal of Sociology, 100: 422-452.

Kerckhoff A C. (1963): 'Patterns of homogamy and the field of eligibles', Social Forces, 64: 289-297.

Kiernan K E. (1986): 'Teenage Marriage and Marital Breakdown: A Longitudinal Study', Population Studies, 40.1: 35-54.

Kingston P W, Finkel S E. (1987): 'Is There a Marriage Gap in Politics?', Journal of Marriage and the Family, 49.1: 57-64.

Lampard R. (1992): An Empirical Study of Marriage and Social Stratification. D.Phil. thesis: University of Oxford.

Mare R D. (1991): `Five decades of educational assortative mating', American Sociological Review, 56: 15-32.

Morgan B S. (1981): 'A Contribution to the Debate on Homogamy, Propinquity and Segregation', Journal of Marriage and the Family, 43: 909921.

Norusis M J. (1993): SPSS for Windows Advanced Statistics Guide Release 6.0. Chicago: SPSS Inc.

Peach C. (1974): `Homogamy, propinquity and segregation: a re-evaluation', American Sociological Review, 39.5: 636-641. 
Penn R D, Dawkins D C. (1983): `Structural Transformations in the British Class Structure: A Log-Linear Analysis of Marital Endogamy in Rochdale 1856-196', Sociology, 17.4: 506-523.

Plutzer E, McBurnett M. (1991): `Family Life and American Politics: The "Marriage Gap" reconsidered', Public Opinion Quarterly, 55.1: 113-127.

Ramsoy N R. (1966): 'Assortative Mating and the Structure of Cities', American Sociological Review, 31: 773-786.

Stier H, Shavit Y. (1994): `Age at marriage, sex-ratios, and ethnic heterogamy', European Sociological Review, 10.1: 79-87.

Swaddle K M O, Heath A F. (1989): 'Official and Reported Turnout in the British General Election of 1987', British Journal of Political Science, 19: 537-570.

Tzeng M S. (1992): `The Effects of Socioeconomic Heterogamy and Changes on Marital Dissolution for First Marriages', Journal of Marriage and the Family, 54.3: 609-619.

Ultee W C, Luijkx R. (1990): `Educational Heterogamy and Father-to-Son Occupational Mobility in 23 Industrial Nations: General Societal Openness or Compensatory Strategies of Reproduction?', European Sociological Review, 6.2: 125-149. 